\title{
Measurements of debris flow velocity through cross-correlation of instrumentation data
}

\author{
M. Arattano ${ }^{1}$ and L. Marchi ${ }^{2}$ \\ ${ }^{1}$ CNR-IRPI Torino, Strada delle Cacce 73, 10135 Torino, Italy \\ ${ }^{2}$ CNR-IRPI Padova, Corso Stati Uniti 4, 35127 Padova, Italy
}

Received: 16 September 2004 - Revised: 4 January 2005 - Accepted: 12 January 2005 - Published: 25 January 2005

Part of Special Issue "Landslides and debris flows: analysis, monitoring, modeling and hazard"

\begin{abstract}
Detection of debris flow occurrence can be efficiently obtained through different types of sensors. A pair of ultrasonic sensors placed at a known distance from each other along a torrent have been used as a method to obtain mean front velocity of debris-flows, in addition to their use as detectors of debris flow occurrence. Also seismic and acoustic sensors have been employed to measure debris-flow front velocity and discharge in the same manner. In order to obtain velocity measurements, however, these methods require the presence of a well identifiable and defined main front in the debris flow wave. The time lag between the recordings of the front of the wave at two consecutive stations allows an estimation of its mean velocity. When a well-defined front is not present and no recurrent feature can be found along the wave, the measurement of velocity may prove difficult. The crosscorrelation technique may help identifying the mean velocity of the flow in such cases. In fact, cross correlation allows to determine the mean time lag elapsed between the recording of two sets of data of the same event at different positions. This technique may be also used to measure velocity using signals coming from different types of sensors, for instance where a ground vibration detector has been placed along a torrent where an ultrasonic sensor was already present or viceversa. An application has been made using field data recorded through seismic and ultrasonic sensors in a small instrumented catchment in the Italian Alps (Moscardo Torrent).
\end{abstract}

\section{Introduction}

In hydraulics, several methods exist to measure flow velocity and discharge in natural channels. Velocity measurements are made through current meters, weirs, Venturi flumes, Parshall flumes, chemical tracers, etc. (Chow, 1959). Less precise methods resort to floating objects thrown in the channel

Correspondence to: M. Arattano

(m.arattano@irpi.to.cnr.it) to measure surface velocity or the surveying of the deposits left after the occurrence of a flood event (slope area method, lateral super elevation formula).

The velocity of debris-flows cannot be easily measured through all these hydraulic techniques. Debris-flow fronts commonly contain large boulders and their tails, which are certainly more fluid, remain charged with pebble-sized fragments. This impedes the use of current meters, weirs and flumes that would be damaged or destroyed by the passage of the flow and require the use of non-contact sensors (Itakura and Suwa, 1989; Zhang, 1993; Chang, 2003; Huang et al., 2003; Itakura and Sawada 2003). Recently some attempts have been made, in Europe and in Japan, to use detectors that can be immersed in the debris flow mixture (Itakura et al., 2000; Hanisch et al., 2003), however field data regarding the efficiency of these tools are still lacking.

The sudden, often unpredictable, occurrence of debrisflows makes it very difficult for observers to be present at the moment of their occurrence. This impedes the use of chemical tracers and other techniques that require an operator on the scene of the event when it occurs, such as throwing floating objects in the channel to measure surface velocity. The difficulties in determining reliably the rheological properties of the flowing mixture may also make uncertain the use of methods based on the surveying of the tracks left after the occurrence of the events, even though the superelevation formula is often used for this purpose.

As mentioned earlier, remote sensors are most suitable for measurements of debris-flow velocity. Spatial filter velocimetry and electromagnetic Doppler speedometers have been used for continuous measurements of surface velocity (Itakura et al., 1985; Itakura and Suwa, 1989; Suwa et al., 1993; Inaba et al., 1997). Discontinuous measurements have been obtained placing a pair of ultrasonic sensors at a known distance from each other along the torrent. These have been used as a method to obtain mean front velocity of debrisflows (Pierson, 1986; Arattano et al., 1997). Seismic and acoustic sensors have been also employed to measure debrisflow front velocity and discharge (Itakura et al., 1997; Arat- 

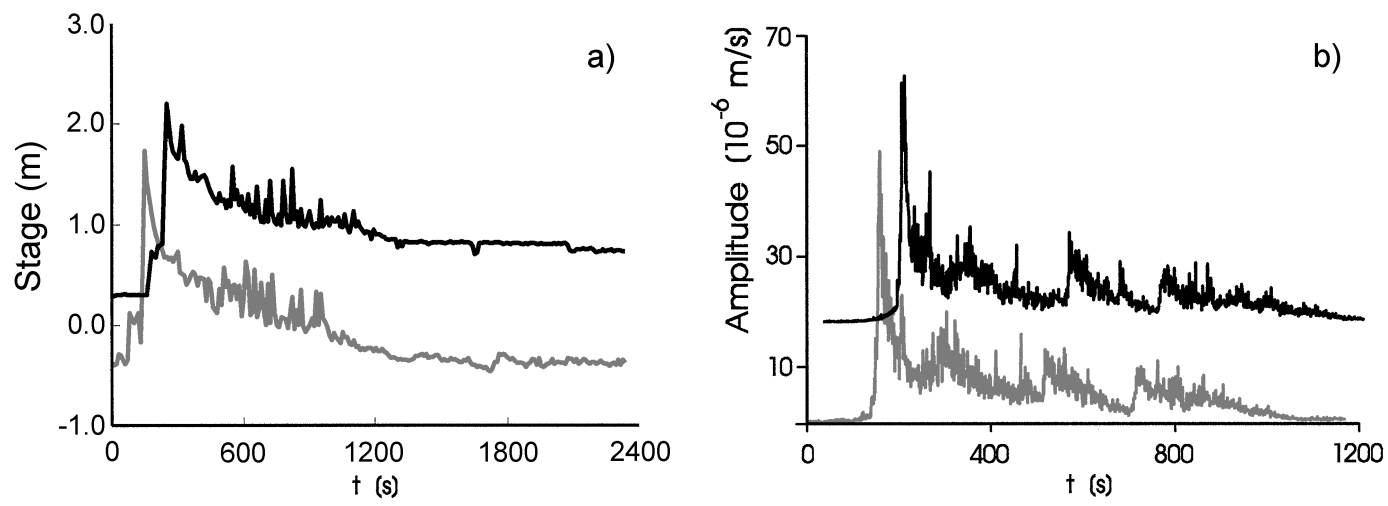

Fig. 1. (a) stage hydrographs recorded by a pair of ultrasonic sensors placed at a distance of $300 \mathrm{~m}$ (debris flow of $11 \mathrm{July} 1993$ ); (b) graphs of Amplitude versus time recorded by a pair of ground vibration sensors placed at a distance of $300 \mathrm{~m}$ (debris flow of $22 \mathrm{June} 1996$ ) (see Arattano and Moia, 1999 for a discussion on the meaning of Amplitude). Both events show the presence of a well identifiable and defined main front in the debris flow wave.

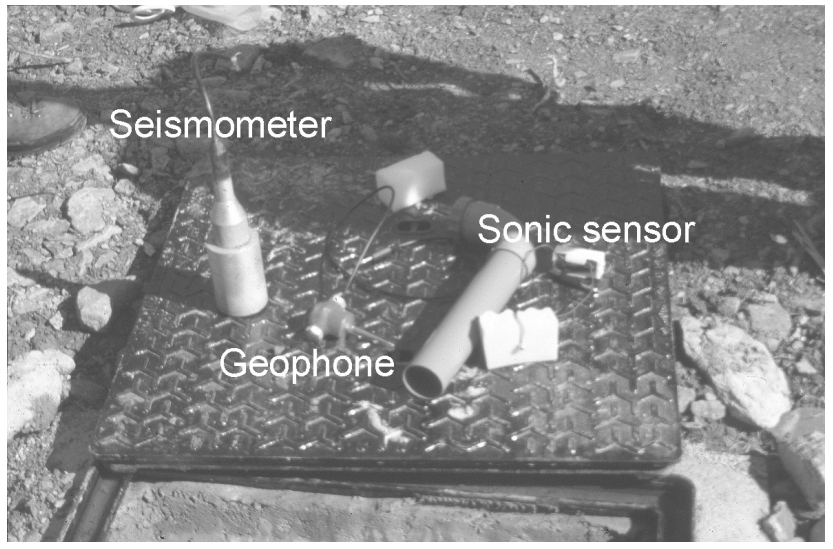

Fig. 2. Seismometer (seismic sensor), geophone and sonic sensor (provided by Y. Itakura - Shiga University, Japan) installed in the Moscardo Torrent. These sensors can be placed outside the channel, need neither visibility of the torrent nor structures to sustain them (they can be placed in a hole in the ground).

tano and Moia, 1999). All these methods require, in order to allow velocity measurements, the presence of a well identifiable and defined main front in the debris flow wave (Fig. 1). The time lag between the recordings of the front of the wave at two consecutive stations allows an estimation of its mean velocity that is given by the ratio between the distance of the sensors and the time lag.

However, although the sudden rise of recorded signals clearly indicates the occurrence of a debris flow, an unique, well-defined debris flow front is not always present, at least upstream of the fan apex (Arattano, 2000, 2003). In these cases, the recorded graphs, both from ultrasonic and seismic sensors, do not show well-defined peaks that can be used for velocity measurements. In order to use such graphs for velocity measurement purposes, the use of cross-correlation technique (described in Sect. 3) may help and provide a good solution.
The applications presented in this paper regard the Moscardo Torrent, a small stream of the Eastern Italian Alps equipped for debris-flow monitoring. Details about the instrumentation installed and the data recorded are reported in Marchi et al. (2002).

\section{Different types of sensors for debris-flow detection}

The various types of sensors that can be used to monitor debris flows and detect their occurrence (ground vibration sensors, sonic sensors, ultrasonic sensors, videocameras, electromagnetic doppler speedometers, spatial filter velocimeters, trip wires) are suitable to different employment, according to their characteristics and have different installation and operational problems.

Ultrasonic sensors, for instance, need to be hung over the torrent through wires or more complex structures that are difficult to install where steep and unstable slopes are present along the banks of the torrent. Trip wires that are broken by the passage of the flow cannot detect subsequent flows without maintenance, are subject to breakage by animals or other similar accidental occurrences and are also difficult to install along steeps slopes. Doppler speedometers (Suwa et al., 1993) are quite expensive and still require a clear visibility of the torrent bed as well as a structure to sustain them that needs a safe place for its installation. The same is true of spatial-filter speedometers (Itakura et al., 1985; Itakura and Suwa, 1989) and of video cameras (Inaba et al., 1997). These latter may also have problems monitoring debris flows occurring at night.

On the contrary, ground vibration sensors (seismic sensors, geophones, sonic sensors, Fig. 2) can be also placed quite far from the torrent bed, they need neither visibility of the torrent, nor structures to sustain them, nor have they any particular problem at night. However, ground vibration sensors may cause difficulties in interpretation of their recordings if placed near a highway, a railroad or other vibration sources. 

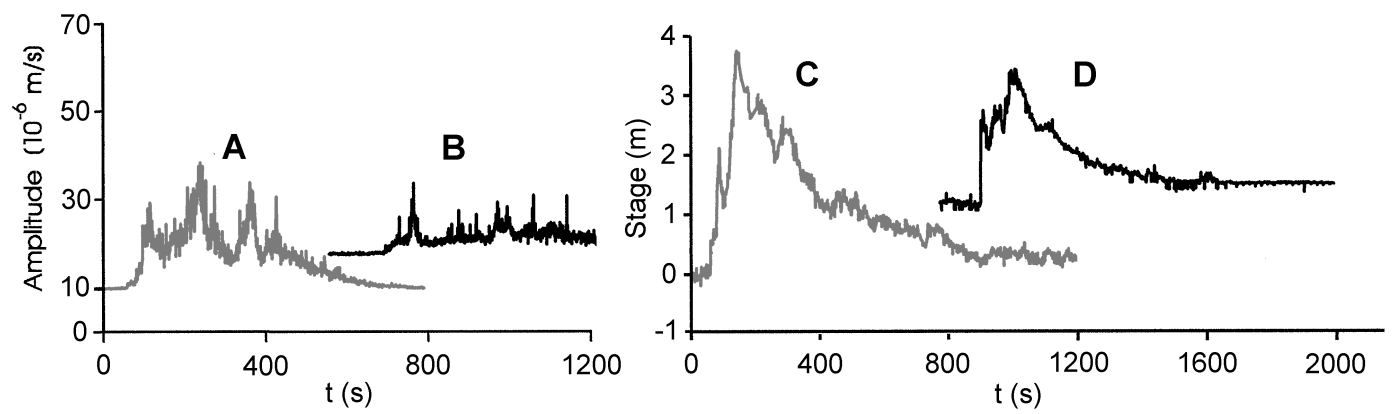

Fig. 3. Debris flow of 8 July 1996. Signals recorded along the torrent from upstream (left) to downstream (right) using different types of sensors: A) and B) seismic recordings; C) and D) ultrasonic recordings. The graphs have been shifted to obtain a more understandable drawing: graph A and B were recorded by sensors placed at a distance of few hundreds meters and are only separated by few tens of seconds. Graphs $\mathrm{C}$ and $\mathrm{D}$ were recorded about $800 \mathrm{~m}$ downstream of the previous graphs and they also were recorded by sensors placed at a distance of few hundreds meters and are only separated by few tens of seconds.

For these reasons, when a torrent is instrumented for monitoring and detection purposes, normally all those sensors requiring visibility of the torrent and structures to sustain them are placed on the fan, where structural supports, for instance, can be easily installed on the torrent banks. On the contrary the sensors that can be also placed far from the torrent bed can be installed also upstream of the fan where the collection of data is still of great interest but the slopes are steeper and would make it much more difficult to install and maintain support structures.

These factors cause difficulties when the signals obtained from different sensors need to be used to calculate velocity of propagation of the debris flow wave. A graph obtained upstream of the fan apex using ground vibration detectors might appear as that shown in Fig. 3 (left, graphs A and B). The graph of the same debris flow event recorded on the fan, $800 \mathrm{~m}$ downstream, through ultrasonic detectors might appear very different as that shown in Fig. 3 (right, graphs $\mathrm{C}$ and D). Even knowing the exact distance between the two different sensors and having the clocks of the two recording systems synchronized, how would one chose the time lag between the occurrence of the event at the two sites? A reference feature should be chosen to calculate that time lag, but it would be very difficult to identify. Again, cross-correlation might help in solving the problem offering a reliable and objective choice of the time lag to use.

\section{Cross-correlation function}

In general, cross-correlation can be defined as the correlation of a series with another series, shifted by a particular number of observations. Cross-correlation is commonly used in signal processing (Stearns and David, 1996). When two time series $\left(x_{k}, y_{k}\right)$ having $M$ samples are available:

$$
\begin{aligned}
& {\left[x_{k}\right]=\left[x_{0}, x_{1}, x_{2}, \ldots ., x_{M-1}\right]} \\
& {\left[y_{k}\right]=\left[y_{0}, y_{1}, y_{2}, \ldots ., y_{M-1}\right]}
\end{aligned}
$$

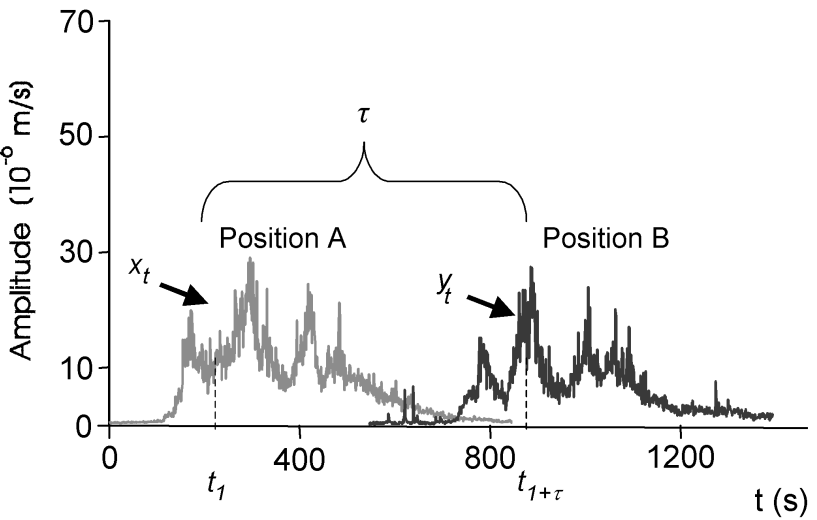

Fig. 4. Principle of cross-correlation: two signals have been recorded at two positions $\mathrm{A}$ and $\mathrm{B}$. The different form of the signals does not allow to easily establish how much time has elapsed between the recordings. Multiplying each value of the first signal for the corresponding value of the second signal recorded at the same time $t$ increased of an amount $\tau$ it is possible to find the value of $\tau$ that maximizes this product (through the construction of the cross-correlation function $\phi_{y x}$ ). This value of $\tau$ gives an objective evaluation of the time elapsed between the recordings.

then the cross-correlation function, $\phi_{y x}$, is defined as:

$\phi_{y x}(\tau)=\sum_{t=0}^{M-1} x_{t} y_{t+\tau}$

In case of the signals recorded by two stations (seismic or ultrasonic) placed at a known distance along a torrent as in Fig. 1, $x_{t}$ is the function expressing the signal recorded at the first, upstream station at the time $t$ and $y_{t+\tau}$ is the function expressing the signal recorded at the second, downstream station at the time $t+\tau ; \tau$ is the time lag (unknown) elapsed between the recording of the two time series.

In order to calculate velocity we need to know the time lag elapsed between the appearance of the event at the upstream station and the appearance of the event at the downstream one. The maximum of the function $\phi_{y x}$ locates the time lag 
Table 1. Values of $\tau$ from the cross-correlation function and velocity estimations for the debris flows recorded in the Moscardo Torrent through ground vibration sensors.

\begin{tabular}{|c|c|c|c|c|c|c|c|c|c|c|}
\hline & \multicolumn{2}{|c|}{ Sensor 1-2 } & \multicolumn{2}{|c|}{ Sensor 2-3 } & \multicolumn{2}{|c|}{ Sensor 3-4 } & \multicolumn{2}{|c|}{ Sensor 2-4 } & \multicolumn{2}{|c|}{ Sensor 1-4 } \\
\hline & $\begin{array}{c}\tau \\
(\mathrm{s})\end{array}$ & $\begin{array}{l}\text { Vel. } \\
(\mathrm{m} / \mathrm{s})\end{array}$ & $\begin{array}{c}\tau \\
(\mathrm{s})\end{array}$ & $\begin{array}{l}\text { Vel. } \\
(\mathrm{m} / \mathrm{s})\end{array}$ & $\begin{array}{c}\tau \\
(\mathrm{s})\end{array}$ & $\begin{array}{l}\text { Vel. } \\
(\mathrm{m} / \mathrm{s})\end{array}$ & $\begin{array}{c}\tau \\
(\mathrm{s})\end{array}$ & $\begin{array}{l}\text { Vel. } \\
(\mathrm{m} / \mathrm{s})\end{array}$ & $\begin{array}{c}\tau \\
(\mathrm{s})\end{array}$ & $\begin{array}{c}\text { Vel. } \\
(\mathrm{m} / \mathrm{s})\end{array}$ \\
\hline 5 July 1995 & & & 33 & 3.0 & 33 & 3.0 & 58 & 3.4 & & \\
\hline 22 June 1996 & 11 & 9.1 & 13 & 7.7 & 14 & 7.1 & 27 & 7.4 & 37 & 8.1 \\
\hline 8 July 1996 & 17 & 5.9 & 18 & 5.6 & 13 & 7.7 & 26 & 7.7 & 44 & 6.8 \\
\hline \multirow[t]{3}{*}{24 July 1997} & 18 & 5.6 & 22 & 4.5 & 18 & 5.6 & 39 & 5.1 & 56 & 5.4 \\
\hline & \multicolumn{2}{|c|}{ Sensor 1-2 } & \multicolumn{2}{|c|}{ Sensor 2-3 } & \multicolumn{2}{|c|}{ Sensor 1-3 } & & & & \\
\hline & $\begin{array}{c}\tau \\
(\mathrm{s})\end{array}$ & $\begin{array}{l}\text { Vel. } \\
(\mathrm{m} / \mathrm{s})\end{array}$ & $\begin{array}{c}\tau \\
(\mathrm{s})\end{array}$ & $\begin{array}{l}\text { Vel. } \\
(\mathrm{m} / \mathrm{s})\end{array}$ & $\begin{array}{c}\tau \\
(\mathrm{s})\end{array}$ & $\begin{array}{l}\text { Vel. } \\
(\mathrm{m} / \mathrm{s})\end{array}$ & & & & \\
\hline 23 July 2004 & 18 & 4.8 & 27 & 6.1 & 43 & 5.6 & & & & \\
\hline
\end{tabular}
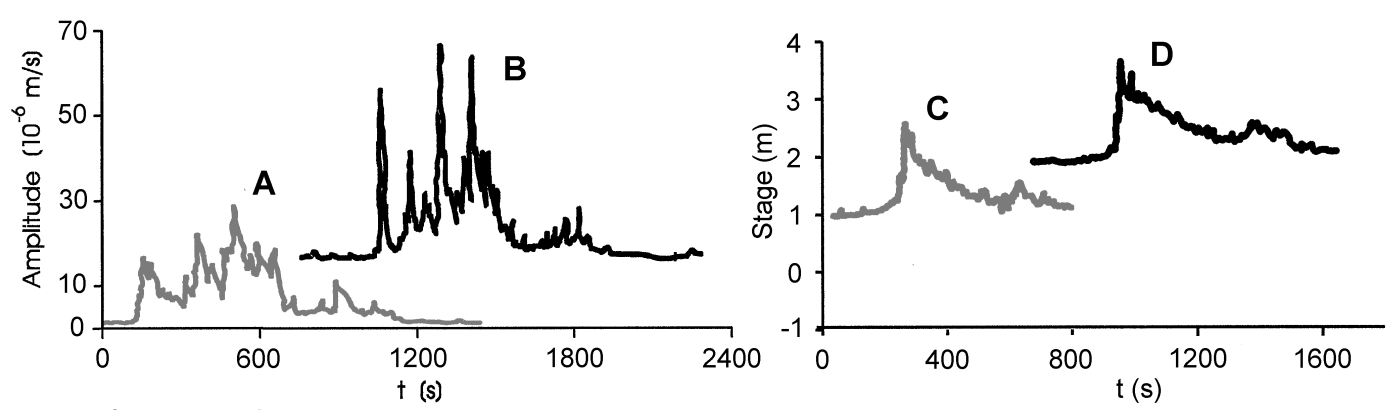

Fig. 5. Debris flow of 23 July 2004. Signals recorded along the torrent from upstream (left) to downstream (right) through different types of sensors: A) and B) seismic recordings C) and D) ultrasonic recordings. The graphs have been shifted like in Fig. 3.

we are looking for, which is given by the value of $\tau$ that corresponds to that maximum.

Figure 4 shows graphically the principle of cross correlation. Two signals $x$ and $y$ have been recorded along a torrent at two positions $\mathrm{A}$ and $\mathrm{B}$. If we calculate the function $F(t)$ given by the sum of the products of the two signals:

$F(t)=\sum_{t=0}^{M-1} x_{t} y_{t}$

this would be zero: the value of $x$ at $t_{1}$ would be in fact multiplied by the value of $y$ at $t_{1}$ which is practically zero (the event has not yet reached the sensor B at the time $t_{1}$ ).

However, if we multiply the value of $x$ at $t_{1}$ by the value of $\mathrm{y}$ at $t_{1+\tau}$ (Fig. 4) the result would be certainly different from zero if $\tau$ is close enough to the time required by the event to reach the position $\mathrm{B}$.

It can be shown that it is possible to build the function $\phi_{y x}(\tau)$ and that this function will have a maximum for the value of $\tau$ which gives the time lag elapsed between the detection of the signal at the two positions A and B. In fact, the maximum will occur for the best possible superposition of the two signals: even though the signal may have changed its form between the two detecting stations $\mathrm{A}$ and $\mathrm{B}$, the best superposition is ideally equivalent to the arrival of the wave with the form recorded in A to the position B.

This offers a method for an objective and quick assessment of velocity, even when no easily identifiable feature is present in the signal and the signals are different in form.

\section{Application of cross-correlation for velocity assess- ment}

The cross-correlation technique has been applied to debrisflow records obtained through different types of sensors in the Moscardo Torrent. Signals had been recorded that were obtained by the same type of sensor but that did not show easily recognizable features to be used for velocity estimations. Other signals had been recorded by different types of sensors that did not allow an easy estimation of velocity because of their difference in form (Figs. 3 and 5). Cross-correlation has been applied to solve both problems mentioned above.

Table 1 shows the velocity estimations performed for signals obtained by the same type of sensor. In Fig. 6, the cross correlation function is shown for two of the signals that have been processed. In 1995, 1996 and 1997, four seismic sensors had been installed along a straight reach of the torrent a few hundred meters upstream of the fan apex (Arattano and 


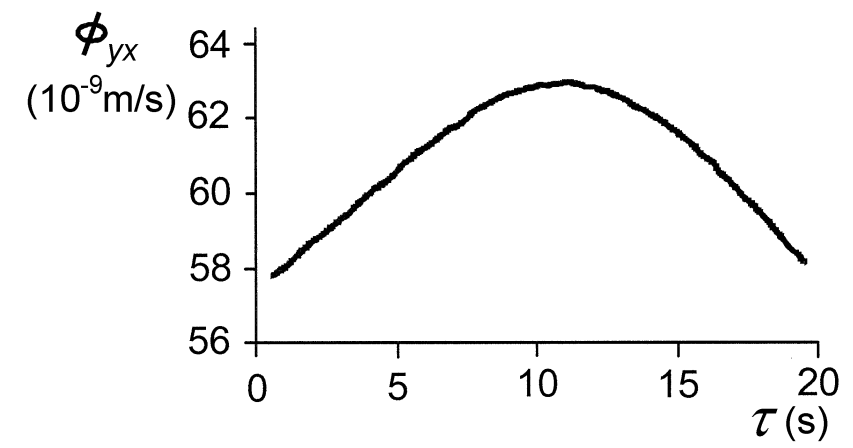

Fig. 6. Cross correlation function for the signals recorded at the seismic sensors 1 and 2 on 22 June 1996.

Moia, 1999). The sensors were located at distances of about $100 \mathrm{~m}$ from each other. In 1995, the most upstream sensor did not properly work and only the data recorded by the other three sensors were available. In 2004, the seismic network consisted of only three sensors. The distances between the sensors were about $85 \mathrm{~m}$ (sensors 1 and 2) and $165 \mathrm{~m}$ (sensors 2 and 3). Cross-correlation has allowed us to determine the values of the time lag $\tau$ between the appearance of the signal at the different sensors.

Velocity measurements without using cross-correlation were possible only for two of the four recorded events, namely, the events that occurred on 22 June 1996 and on 24 July 1997. These events presented some features (a main peak in the front part of the signal) that allowed for the velocity measurements. Figure 1b shows the 22 June 1996 event: the peak used for the measurement is clearly visible. In Fig. 7, the measurements made without cross-correlation are compared with the velocity estimations obtained with crosscorrelation. The least squares regression of the data shown in Fig. 7 has an $R^{2}$ of 0.76 . The agreement between two series of measurements is fairly good, particularly if we consider that the cross-correlation gives an estimation of the average velocity of the entire moving mass and not of a single feature, such as the debris-flow front.

In the other events, the lack of a recognizable feature in the seismic graphs prevents the use of standard techniques for velocity assessment, so that a comparison with the results of cross-correlation is not possible. It is possible to note, however, that the velocities assessed using cross-correlation (Table 1) are consistent with those recorded in the Moscardo Torrent since the beginning of monitoring activities (Marchi et al., 2002; Arattano and Moia, 1999).

Velocity measurement between the seismic and the ultrasonic stations in the Moscardo Torrent were not possible for previously recorded events because the seismic network placed upstream from the fan apex and the ultrasonic network on the fan were not time synchronized. However the crosscorrelation function obtained from the two types of signals recorded in 1996 (22 June and 8 July) and on 23 July 2004 showed a very neat maximum: thus the cross-correlation technique seems to offer a good method for an objective

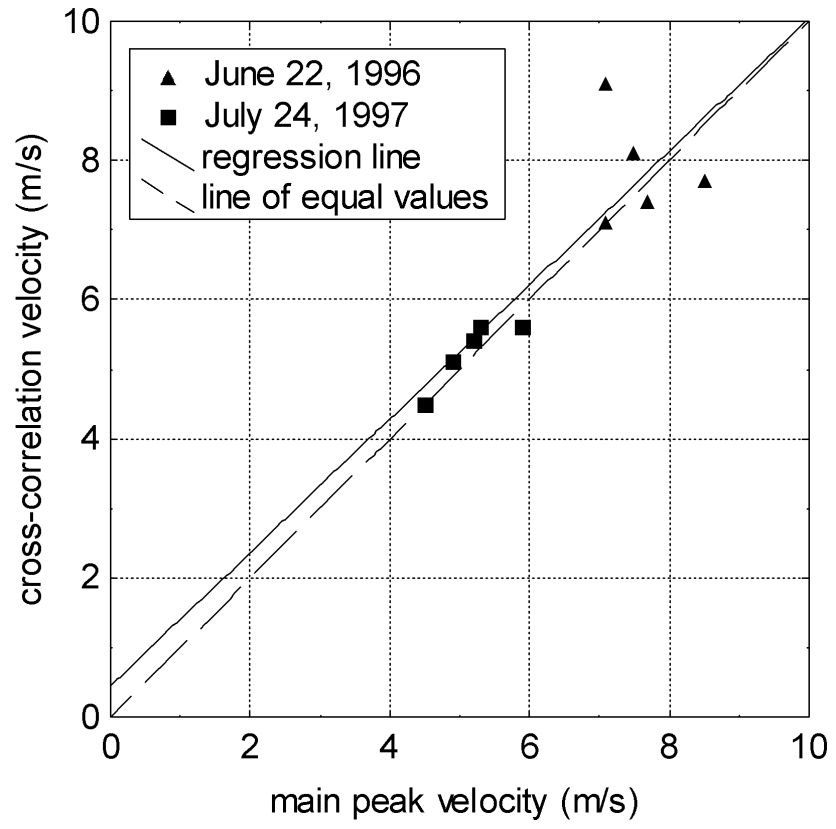

Fig. 7. Comparison between velocity estimations through crosscorrelation and measurements obtained calculating the ratio of the distance between the sensors to the time lag between the appearance of a signal peak at two consecutive detectors.

estimation of velocity using signals coming from different types of detectors once time synchronization between different recorders exists.

\section{Conclusions}

A pair of ultrasonic, seismic or acoustic sensors placed at a known distance from each other along a torrent offer a method to obtain mean front velocity of debris-flows. The time lag between the recordings of the front of the wave at two consecutive gauging stations allows for an assessment of mean velocity. The presence of a well-defined main front in the debris flow wave is required however, in order to allow velocity measurements. When a clearly-defined front is not present and no recurrent features can be found along the wave, measurement of velocity is often difficult. In such cases the cross-correlation technique helps objectively defining the mean velocity of the flow. This technique may also be used to measure velocity using signals coming from different types of sensors placed along a torrent. An application has been carried out using field data recorded through seismic and ultrasonic sensors in the Moscardo Torrent, a small instrumented catchment in the Italian Alps. The results show the consistency of velocity values assessed through crosscorrelation with those obtained in the same basin by means of standard techniques.

Acknowledgements. The research presented in this paper has been carried out within the context of the E.U. Project THARMIT (Project No. EVG1-CT-1999-00012), the GNDCI Project 13/Line 3 
"Sistemi per la mitigazione del rischio derivante da colate detritiche" and the Italy-Japan collaboration on geological hazards, funded by the Italian Ministry of Foreign Affairs (Geo-Risk Joint Lab). The authors wish to thank C. Ancey and J. A. Coe for their valuable comments on this paper.

Edited by: M. Jaboyedoff

Reviewed by: C. Ancey and J. A. Coe

\section{References}

Arattano, M., Deganutti, A. M., and Marchi, L.: Debris flow monitoring activities in an instrumented watershed on the Italian Alps, in: Proceedings, First International Conference on Debrisflow Hazards Mitigation: Mechanics, Prediction and Assessment, edited by: Chen, C. L., ASCE, New York, 506-515, 1997.

Arattano, M. and Moia, F.: Monitoring the propagation of a debris flow along a torrent, Hydrol. Sci. J., 44, 811-823, 1999.

Arattano, M.: On debris flow front evolution along a torrent, Phys. Chem. Earth B, 25, 733-740, 2000.

Arattano, M.: Monitoring the presence of the debris flow front and its velocity through ground vibration detectors, in: Proceedings, Third International Conference on Debris-flow Hazards Mitigation: Mechanics, Prediction, and Assessment, edited by: Rickenmann, D. and Chen, C. L., Millpress, Rotterdam, 719-730, 2003.

Chang, S. Y.: Evaluation of a system for detecting debris flows and warning road traffic at bridges susceptible to debris-flow hazard, in: Proceedings, Third International Conference on Debrisflow Hazards Mitigation: Mechanics, Prediction, and Assessment, edited by: Rickenmann, D. and Chen, C. L., Millpress, Rotterdam, 731-742, 2003.

Chow, V. T.: Open channel hydraulics, McGraw-Hill, New York, 1959.

Huang, C.-J., Yin, H. Y., and Shieh, C. L.: Experimental study of the underground sound generated by debris flows, in: Proceedings, Third International Conference on Debris-flow Hazards Mitigation: Mechanics, Prediction, and Assessment, edited by: Rickenmann, D. and Chen, C. L., Millpress, Rotterdam, 743753,2003

Hanisch, J., Ergenzinger, P., and Bonte M.: Dumpling - an "intelligent" boulder for studying internal process of debris flows, in: Proceedings, Third International Conference on Debris-flow Hazards Mitigation: Mechanics, Prediction, and Assessment, edited by: Rickenmann, D. and Chen, C. L., Millpress, Rotterdam, 843-849, 2003.
Inaba, H., Uddin, M. S., Itakura, Y., and Kasahara, M.: Surface velocity vector field measurement of debris flow based on spatiotemporal derivative space method, in:, Proceedings, First International Conference on Debris-flow hazards mitigation: mechanics, prediction and assessment, edited by: Chen, C. L., ASCE, New York, 757-766, 1997.

Itakura, Y., Ogawa, K., Suwa, H., and Mizuhara, K.: Trends and fluctuation of the surface-velocity of debris flow measured by a non-contact speed sensor with a spatial filter, in: Fluid control and measurement, edited by: Harada, M., Pergamon Press, Tokyo, 781-786, 1985.

Itakura, Y. and Suwa, H.: Measurement of surface velocity of debris flows by spatial filtering velocimetry, Proceedings of the Japan China Symposium on Landslides and Debris Flows, Niigata, Tokyo, Japan, 199-203, 1989.

Itakura, Y., Koga, Y., Takahama, J., and Nowa, Y.: Acoustic detection sensor for debris flow, in: Proceedings, First International Conference on Debris-flow hazard mitigation: mechanics, prediction and assessment, edited by: Chen, C. L., ASCE, New York, 747-756, 1997.

Itakura, Y., Kitajima, T., Endo, K., and Sawada, T.: A new double dual-axes accelerometer debris-flow detection system, in: Proceedings, Second International Conference on Debris-flow Hazards Mitigation: Mechanics, Prediction, and Assessment, edited by: Wieczorek, G. and Naeser, N., Balkema, Rotterdam, 273 281, 2000.

Itakura, Y. and Sawada, T.: An oil immersed microphone sensor for improved debris flow detection, in: Proceedings, Third International Conference on Debris-flow Hazard Mitigation: Mechanics, Prediction, and Assessment, edited by: Rickenmann, D. and Chen, C. L., Millpress, Rotterdam, 863-870, 2003.

Marchi, L., Arattano, M., and Deganutti, A. M.: Ten years of debris flows monitoring in the Moscardo Torrent (Italian Alps), Geomorphology, 46, 1-17, 2002.

Pierson, T. C.: Flow behavior of channelized debris flows, Mount St. Helens, Washington, in Hillslope Processes, edited by: Abrahms, A. D., Allen \& Unwin, Boston, 269-296, 1986.

Stearns, S. D. and David, R. A.: Signal processing algorithms in matlab, Prentice Hall P T R, Upper Saddle River, New Jersey, 372, 1996

Suwa, H., Okunishi, K., and Sakai, M.: Motion, debris size and scale of debris flows in a valley on Mount Yajkedake, Japan, in: Sediment Problems: Strategies for Monitoring, Prediction and Control, Proceedings of the Yokohama Symposium, July 1993, IAHS Publ. No. 217, 239-248, 1993.

Zhang, S.: A comprehensive approach to the observation and prevention of debris flows in China, Nat. Hazards, 7, 1-23, 1993. 